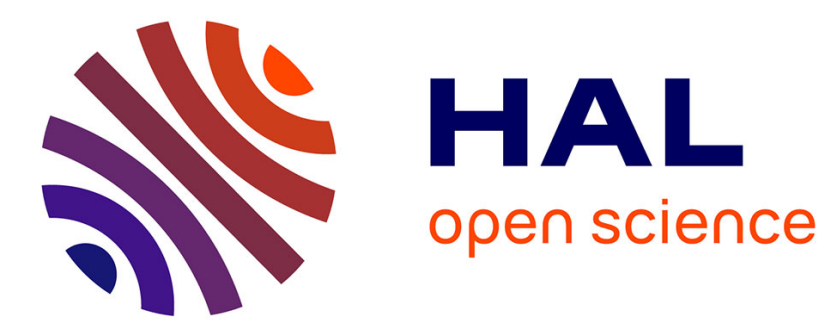

\title{
High connectivity in a long-lived high-Arctic seabird, the ivory gull Pagophila eburnea
}

Glenn Yannic, Jonathan M Yearsley, Roberto Sermier, Christophe Dufresnes,

Olivier Gilg, Adrian Aebischer, Maria V. Gavrilo, Hallvard Strøm, Mark L.

Mallory, R I Guy Morrison, et al.

\section{To cite this version:}

Glenn Yannic, Jonathan M Yearsley, Roberto Sermier, Christophe Dufresnes, Olivier Gilg, et al.. High connectivity in a long-lived high-Arctic seabird, the ivory gull Pagophila eburnea. Polar Biology, 2016, 39 (2), pp.221-236. 10.1007/s00300-015-1775-z . hal-01196647

\section{HAL Id: hal-01196647 https://hal.sorbonne-universite.fr/hal-01196647}

Submitted on 10 Sep 2015

HAL is a multi-disciplinary open access archive for the deposit and dissemination of scientific research documents, whether they are published or not. The documents may come from teaching and research institutions in France or abroad, or from public or private research centers.
L'archive ouverte pluridisciplinaire HAL, est destinée au dépôt et à la diffusion de documents scientifiques de niveau recherche, publiés ou non, émanant des établissements d'enseignement et de recherche français ou étrangers, des laboratoires publics ou privés. 
Glenn Yannic ${ }^{1,2,3^{*}}$, Jonathan M. Yearsley ${ }^{4}$, Roberto Sermier ${ }^{5}$, Christophe Dufresnes ${ }^{5}$, Olivier Gilg $^{3,6}$, Adrian Aebischer ${ }^{3,7}$, Maria V. Gavrilo ${ }^{8,9}$, Hallvard Strøm $^{10}$, Mark L. Mallory ${ }^{11}$, R. I. Guy Morrison $^{12}$, H. Grant Gilchrist ${ }^{13}$, Thomas Broquet ${ }^{14,15}$

1. Département de Biologie, Université Laval, Québec, Québec, G1V 0A6, Canada

2. Canada Research Chair in Polar and Boreal Ecology, Department of Biology, Université de Moncton, Moncton, New-Brunswick, E1A 3E9, Canada

3. Groupe de Recherche en Ecologie Arctique (GREA), 21440 Francheville, France

4. School of Biology and Environmental Science, University College Dublin, Belfield, Dublin, Ireland

5. Department of Ecology and Evolution, University of Lausanne, CH-1015 Lausanne, Switzerland

6. Laboratoire Biogéosciences, UMR CNRS 5561, Equipe Ecologie Evolutive, Université de Bourgogne, 6 Boulevard Gabriel, 21000 Dijon, France

7. Museum of Natural History, Chemin du Musée 6, 1700 Fribourg, Switzerland

8. National Park Russian Arctic, 57 Sovetskikh Kosmonavtov pr., 168000, Archangelsk, Russia

9. Joint Directorate of Taimyr Nature Reserves, 22 Talnakhskaya, 663300, Norilsk, Russia

10. Norwegian Polar Institute, Fram Centre, 9296 Tromsø, Norway

11. Department of Biology, Acadia University, 33 Westwood Avenue, Wolfville, Nova Scotia B4P 2R6, Canada

12. Environment Canada, National Wildlife Research Centre, Ottawa, Ontario, K1A0H3, Canada

13. Environment Canada, National Wildlife Research Centre and Department of Biology, Carleton University, Ottawa, Ontario, K1S5B6, Canada

14. CNRS, team diversity and connectivity of coastal marine landscapes, Station Biologique de Roscoff, 29680 Roscoff, France

15. Sorbonne Universités, UPMC Univ Paris 06, UMR 7144, Station Biologique de Roscoff, 29680 Roscoff, France 
Correspondence and present address:

Glenn Yannic, glenn.yannic@gmail.com

LECA - Laboratoire d'Ecologie Alpine - CNRS UMR 5553

Université Savoie Mont Blanc

38

73376 Le Bourget-Du-Lac cedex, France

$+(33) 0479758865$

40

Keywords: natal dispersal, breeding dispersal, effective number of breeders, population 42 genetic structure, overlapping generation model 


\section{Abstract}

Species may cope with rapid habitat changes by distribution shifts or adaptation to new conditions. A common feature of these responses is that they depend on how the process of dispersal connects populations, both demographically and genetically. We analyzed the genetic structure of a near threatened High Arctic seabird, the ivory gull (Pagophila eburnea) in order to infer the connectivity among gull colonies. We analyzed 343 individuals sampled from 16 localities across the circumpolar breeding range of ivory gulls, from northern Russia to the Canadian Arctic. To explore the roles of natal and breeding dispersal we developed a population genetic model to relate dispersal behavior to the observed genetic structure of worldwide ivory gull populations. Our key finding is the striking genetic homogeneity of ivory gulls across their entire distribution range. The lack of population genetic structure found among colonies, in tandem with independent evidence of movement among colonies, suggests that on-going effective dispersal is occurring across the Arctic Region. Our results contradict the dispersal patterns generally observed in seabirds where species movement capabilities are often not indicative of dispersal patterns. Model predictions show how natal and breeding dispersal may combine to shape the genetic homogeneity among ivory gull colonies separated by up to $2800 \mathrm{~km}$. Although field data will be key to determine the role of dispersal for the demography of local colonies and refine the respective impacts of natal versus breeding dispersal, conservation planning needs to consider ivory gulls as a genetically homogeneous, Arctic-wide metapopulation effectively connected through dispersal. 


\section{Introduction}

The distribution of natural habitats worldwide is currently changing as a direct consequence of global climate trends, and this is happening particularly fast in the Arctic, where climate warming is maximal (ACIA 2004; IPCC 2007). Species that live in the Arctic or in other rapidly changing environments might cope with this rapid change by shifting their distributions, by adjusting through phenotypic plasticity or by evolving adaptations to the new local climatic conditions (reviewed by Chen et al. 2011; Gienapp et al. 2008; Gilg et al. 2012; Hoffmann and Sgro 2011; Parmesan 2006). These responses partly depends on the process of dispersal; that is, the movement of individuals between birth and reproduction (natal dispersal), and possibly between successive reproduction events (breeding dispersal). Besides its role in the spatial structure and demographic dynamics of populations, dispersal is important in the context of habitat change because it is one key driver of the potential rate of spread of a population and, as the process by which genes are moved among populations, it influences the rate of adaptation to changing conditions and the potential for evolutionary rescue (Bell and Gonzalez 2011; Travis et al. 2013). Thus, understanding, predicting and managing biodiversity responses to rapid climate change demands a full consideration of a species' dispersal characteristics and their demographic and genetic consequences.

We focus here on the ivory gull Pagophila eburnea, a bird that completes its life-cycle entirely in the Arctic. Over its entire breeding range (Canadian Arctic, Greenland, Svalbard and Russian Arctic islands) it breeds either on inland cliffs and 'nunataks', i.e. rocky outcrops emerging from icecaps, or on high-Arctic barren islands or flatlands (Gilg et al. 2009; Mallory et al. 2008). In Canada, where the status of the species has been designed 'Endangered' (COSEWIC 2006), studies indicated that $80 \%$ of the breeding population was lost during the past 20 years (Gilchrist and Mallory 2005). The species is listed as Near Threatened by the IUCN (BirdLife International 2012) and an international circumpolar 
'Conservation Strategy and Action Plan' has been presented by leading seabird experts from Arctic countries to gain more insight into how this bird responds to increasing threats from disappearance of sea ice habitat, natural resource exploration and increased contaminant loads (Gilchrist et al. 2008).

Ivory gulls are capable of travelling thousands of kilometers either on single foraging trips or to reach wintering grounds in the north Pacific (Bering Sea and Sea of Okhotsk) and in the northwest Atlantic (Davis Strait and Labrador Sea) where most of the world population is thought to spend the winter (Gilg et al. 2010; Mallory et al. 2008). However, most seabirds have an extraordinary ability to travel long distances and yet show evidence of restricted gene flow and exhibit high levels of philopatry, sometimes returning to breed within a few meters of their natal nest (Friesen et al. 2007). A species' movement capabilities thus do not automatically inform us about demographic and genetic connectivity among colonies. This is the "seabird paradox", i.e., the apparent paradox between high vagility and low effective dispersal (Milot et al. 2008).

Dispersal may take place at different stages of an individual's life. For ivory gulls, natal dispersal may happen during the two first years of life before the individual becomes sexually mature and joins a breeding colony. However, the behavior of ivory gulls during that time is almost completely unknown. In addition, adult ivory gulls may disperse among colonies from one breeding season to the next. Such breeding dispersal could effectively contribute to demographic and genetic exchanges among colonies, but our knowledge of these aspects for ivory gulls currently relies only on incidental observations (O. Gilg, A. Aebischer and M.L. Mallory, unpubl. data).

Here we take a genetic approach to investigating dispersal in order to complement ongoing mark-recapture and satellite tracking efforts (Gilg et al. 2010; Spencer et al. 2014). Genetic data can complement other approaches to measure dispersal either by providing direct 
information on individual movements (e.g., through parentage or population assignment) or indirect signatures of dispersal patterns (e.g., through analyses of genetic structure).

Disentangling the effects of natal dispersal and breeding dispersal on realized gene flow is, however, challenging, and has rarely been addressed in the molecular ecology literature (Broquet and Petit 2009), although Rousset (2001) and Laporte and Charlesworth (2002) present general class-structured models that lay the foundations to such an endeavor.

The aim of this study was to explore population structure and spatial dispersal pattern in the ivory gull and to infer natal versus breeding dispersal among colonies. For that purpose, we analyzed a genetic data set representative of the entire species range and developed a population genetic model to infer lower bounds on natal and breeding dispersal consistent with the observed genetic structure of ivory gull populations worldwide.

\section{MATERIAL AND Methods}

\section{Study species}

The ivory gull is a long-lived High Arctic seabird (annual survival estimated to 0.86; Stenhouse et al. 2004; and maximum record 28 years; Mallory et al. 2012), which is associated with sea ice all year round (Gilg et al. 2010; Spencer et al. 2014). Breeding colonies are scattered in Arctic Canada, Greenland, Svalbard, and the northern islands of Russia in the Barents and Kara seas (Table 1). The current total global population of the ivory gull was estimated to be approximately 19,000-27,000 breeding pairs (BirdLife International 2012). The Russian population is estimated to number in the range of $14,500-22,000$ individuals (Gavrilo 2011). The population in Canada has declined since the 1980s (Mallory et al. 2008). In Norway (Svalbard) the population probably declined in the first part of last century, but after 1970 the trend is uncertain (Mallory et al. 2008). Population trends in Greenland are unclear due to sparse historical information (Gilg et al. 2009). Ivory gulls are 
thought to first breed after their second year, based on the fact that they acquire adult plumage in their second winter, and that individuals in less than full adult plumage are rarely seen at breeding colonies (Mallory et al. 2008). Unlike most gulls, which regularly lay 3 eggs, the ivory gull usually lays $1-2$ eggs, more rarely 3 eggs. Most of the world population is thought to spend the winter in two main wintering grounds (Mallory et al. 2008): the north Pacific (Bering Sea and Sea of Okhotsk) and the northwest Atlantic (Davis Strait and Labrador Sea, Figure 1).

\section{Sample collection}

Field works took place in summers 2006 to 2012, during the breeding season (late June to August). Sample locations were distributed across the entire breeding range of the species, including the Canadian Arctic Archipelago, north-eastern Greenland, Svalbard Archipelago, Franz Josef Land Archipelago, Severnaya Zemlya Archipelago and Kara Sea islands (16 sampling locations overall, listed in Table 1 and Figure 1). We collected samples either in breeding colonies or opportunistically near two military stations where ivory gulls are attracted by food remains (namely Alert, Canada and Station Nord, Greenland). Three nondestructive DNA sampling methods (mouth swabs, plucked feathers and blood) and a noninvasive sampling method (shed feathers) were used. Pieces of tissue were also opportunistically collected on dead birds.

Juveniles (chicks of the year) were sampled in two sites from Greenland in 2009: Amdrup Land and Station Nord (Table 1 and Figure 1) in order to perform parentage analyses. In these cases, buccal swabs and tissue samples were used as DNA sources. All other samples were taken from adult birds, where we considered two classes of individuals according to their breeding status. Field observations suggest that non-breeding adults visit or stay in colonies during the breeding season. Moreover, satellite transmitters indicated that breeding birds 
visited colonies as far as $200 \mathrm{~km}$ from their own breeding colony (O. Gilg \& A. Aebischer, unpublished data). Hence in any one site adult birds were classified as "breeding" only if they were seen hatching eggs or raising chicks, and "unknown status" otherwise. Thus, "unknown" birds included: i) the non-breeding component of the population (the so-called "floaters"; Penteriani et al. 2011), but also ii) birds found in colonies but that were not reproducing locally and that may reproduce elsewhere in an unknown colony; and ii) birds that they were identified from shed feathers collected on the ground. This distinction is relevant for analyzing the genetic structure of colonies since non-breeding birds or individuals lacking information on their breeding location (all called here "unknown") could be transient visitors. Due to field constraints we generally have information on only one of these two classes of adults within each sampling site (reported in Table 1), either because samples were taken only from breeding individuals or because the breeding status was ignored altogether (e.g., shed feathers or transient birds). However in one repeatedly visited site from Greenland (called Station Nord), we could collect precise mark-resight data on both breeding and unknown (see above) individuals, and obtain sizable samples from these two classes of birds (referred to as "breeding" and "unknown" in Table 1).

All samples from Greenland, Norway and Russia (Table 1) were obtained using nondestructive (collection of mouth swabs and plucked feathers) and non-invasive DNA sampling methods (collection of shed feathers) as described in Yannic et al. (2011). In addition, birds from Alert (Canada) were caught with rocket nets near a military base. Immediately following capture, a blood sample (about $0.3 \mathrm{ml}$ ) was collected from the brachial vein in heparinized micro-hematocrit capillary tubes, before release. Blood samples were centrifuged on site at 13,200 g for $15 \mathrm{~min}$. Red blood cells and plasma were separated and stored frozen at $-20^{\circ} \mathrm{C}$ until laboratory analyses). 


\section{DNA extraction and genotyping}

Genomic DNA from all individuals was extracted from shed and plucked feathers, tissue, blood or buccal swab following protocols described in Yannic et al. (2011) (see also Supplementary material 1). Previously optimized microsatellite markers were used in four polymerase chain reaction (PCR) multiplexes, totaling 22 markers (Yannic et al. 2011). For samples obtained from shed feathers we performed three independent PCR replicates of each locus to obtain reliable genotypes (see Yannic et al. 2011). The microsatellite amplicons were loaded on an ABI PRISM 3100 (Applied Biosystems Foster City, CA, USA) automated DNA sequencer. Microsatellite alleles were detected, scored, and manually verified using GENEMAPPER 3.7 (Applied Biosystems).

\section{Genetic structure}

All loci were found to be independent of one another (linkage disequilibrium test performed in FSTAT 2.9.4 (Goudet 2005), using 10000 permutations and p-values adjusted for multiple comparisons using the Benjamini and Yekutieli false discovery rate procedure with initial $\alpha=$ 0.05). We used two sets of loci depending on downstream analyses. All 22 loci were used for the parentage analyses because: i) all genetic data from the juveniles came from good quality samples (tissue and buccal swab); and ii) genotyping errors or null alleles can be identified and taken into account (see below). For the analysis of spatial genetic structure some data come from "low quality" samples (shed feathers, Table 1). Hence for these analyses we used a subset of 13 loci (listed in Table 2) chosen for their polymorphism and reliability as reported in Yannic et al. (2011).

We investigated the differentiation among ivory gulls sampling sites by estimating $F_{\mathrm{ST}}$ (Weir and Cockerham 1984). We ran some of the analyses using only the samples with $>10$ adults. Global $F_{\text {ST }}$ was computed with FSTAT for different combinations of samples: overall adults ( $n$ 
$=15$ localities), over sites with $>10$ adults ( $n=9$ localities), and among breeders only $(n=6$ localities). The significance of the differentiation was tested using two approaches. First we used the $\log$-likelihood $G$ statistic calculated for observed data and compared to that of 10000 randomized datasets obtained through permutation of individuals among samples (as implemented in Fstat; Goudet 2005; Goudet et al. 1996). Second, for a strict comparison with results from our evaluation of power (see below), we also used Fishers' Exact Test as implemented in GENEPOP. In that case the distribution of alleles within individuals is ignored and thus genic rather than genetic differentiation among samples is tested. Furthermore, the null distribution is obtained using a Markov Chain algorithm rather than permutations, performed here with defaults GENEPOP parameters. Pairwise $F_{\mathrm{ST}}$ among all samples were also calculated with FSTAT.

The statistical power to detect a significant genetic heterogeneity at various true levels of differentiation for the present set of samples, number of loci and allele frequencies was evaluated using Powsim 4.1 (Ryman and Palm 2006). Powsim simulates samples of genes from a specified number of populations that have drifted to an expected predefined level of differentiation (measured as $F_{\mathrm{ST}}$ ). These samples are then used for testing genetic homogeneity using Fisher's Exact Test. With this procedure we estimated the power that we had when looking for genetic differentiation using all adults and breeders only (see Table 1). Estimates of power were given by the proportion of significant outcomes when repeating the simulations 1000 times for each level of simulated $F_{\mathrm{ST}}$. The use of post hoc power analyses should however be used with caution as stressed by Hoenig and Heisey (2001). But, here our goal is not to modify a hypothesis test a posteriori (the problematic situation identified by Hoenig and Heisey (2001)) but rather to give an idea of the degree to which our data are informative. 


\section{Reproductive success and effective number of breeders}

To interpret our observations of genetic structure across colonies we needed an estimate of effective colony sizes. This can be approximated using the effective number of breeders $\left(N_{b}\right)$ $\left(N_{b}\right.$; Waples and Teel, 1990), a parameter that depends on the census number of adults in a colony (here noted $N_{c}$ ) and the distribution of reproductive success among individuals within colonies following (Kimura and Crow 1963): $N_{b}=\left(N_{c} k-1\right) /\left[k-1+\left(V_{k} / k\right)\right]$, where $k$ is the mean and $V_{k}$ the variance in reproductive success among individuals. As a first approximation we estimated these figures from field observations of the number of juveniles per nest in colonies Amdrup Land and Station Nord, considering that there are two and only two adults associated with a given nest.

This approach assumes that juveniles within a nest descend from the adult pair providing parental care to these offspring. This is a weak assumption since extra-pair paternity is frequent in socially monogamous birds (Westneat and Stewart 2003), meaning that some males may not have sired the juveniles they are taking care of, whilst other males may have parented offspring with more than one female. Hence males may have a slightly higher variance in reproductive success than those calculated from field observations. To check whether social monogamy reflects the actual breeding system we performed genetic parentage assignments in colony Station Nord, where we had DNA samples from a number of juveniles $(n=20)$ and presumed parents $(n=24)$, that is, adults seen hatching eggs or raising chicks.

Details of the parentage analysis, performed with the method implemented in CoLONY 2.0.4.5 (Jones and Wang 2009; Wang 2012) are described fully in Electronic Supplementary Material (Supplementary material 1). We repeated these analyses in the colony of Amdrup Land, where 65 juveniles (but no parents) were sampled. 
Interpreting genetic differentiation in terms of connectivity and dispersal behavior is not trivial given that it requires some knowledge of the effective number of breeders within colonies ( $\mathrm{Nb}$, which we investigated in this study) and the effect of life-history traits such as longevity and the potential movement behavior of juveniles (natal dispersal) and adults between breeding seasons (breeding dispersal). We therefore used a 2-sample coalescent approach to describe an island model, with overlapping generations and both natal and breeding dispersal. The model is used to explore the dispersal scenarios that are consistent with the observed level of population differentiation (global $F_{S T}$ ) among arctic-wide populations of ivory gulls.

The model builds upon Yearsley et al. (2013) to introduce overlapping generations following the general approach laid out by Laporte and Charlesworth (2002). Each deme contains $N$ diploid non-selfing individuals, of which $N_{a}=v N$ are adults who have survived at least one breeding cycle and $N_{j}=(1-v) N$ are first-year juveniles ( $v$ is the adult survival probability per breeding cycle). One breeding-cycle going forward in time represents a unit time step and is composed of: reproduction, mutation, dispersal, adult mortality, juveniles either mature into adults or die, population regulation (i.e., the population size remains constant at every breeding cycle). The model simplifies certain aspects of the ivory gull's life-history. Maturation for ivory gulls is known to be longer than one year whereas our model, to enable an analytical solution, assumes that a maximum juvenile period of one year. From numerical simulations (results not shown) the effect of a prolonged juvenile stage on $F_{S T}$ is small when adult mortality is low (as for the ivory gull). All adults in the model are assumed to have equal reproductive success. Individual variation in reproductive success and non-breeding adults must be accounted for by the effective population size, $N$. The model also does not describe sex-linked differences in life-history, such as dispersal or survival. At present we do 
not have sufficient sex-specific data for the ivory gull to know whether such differences exist for this species.

The model estimate expected coalescence times, genetic diversities, and $F$-statistics for a DNA sequence under the infinite-sites model (Kimura 1969) with a mutation rate $\mu$ / generation/sequence. For our model parameterizations the force of mutation upon genetic diversities is weak compared to the forces of genetic drift and gene flow. Our model considers the coalescent for a sample of two DNA sequences that are randomly sampled just prior to population regulation. We define three states for a pair of sampled sequences: two sequences in the same diploid individual, two sequences in different individuals in the same deme, and two sequences in different individuals in different demes (states 1, 2 and 3 respectively).

The ancestral history of a pair of sequences can be defined by a transition matrix, $\boldsymbol{G}$, where an element, $G_{i, j}$, gives the probability that a pair of sequences in state $i$ had ancestors from the previous generation in state $j$ (the rate of coalescence per generation for a pair of sequences in state $i$ is then given by $G_{i 0}=1-\sum_{j} G_{i, j}$ ). Using first-step analysis (Wakeley 2009) the expected times to coalescence of two lineages in state $i, T_{i}$, can be calculated by solving

$$
T_{i}=1+\sum_{j=1}^{3} G_{i . j} T_{j}
$$

This equation is analogous to equation 8 in Laporte and Charlesworth (2002), and details of the approach used to derive equation 1 are given in Yearsley et al. (2013). Using Slatkin's approximation (Slatkin 1991), these coalescence times can be used to approximate $F$-statistics in the small mutation limit as

$$
F_{I S}=\frac{T_{2}-T_{1}}{T_{2}}
$$




$$
F_{S T}=\frac{T_{3}-T_{2}}{T_{3}}
$$

Alternatively, mutations can be included in the matrix $\boldsymbol{G}$ and $F$-statistics calculated from recurrence relationships for identity by descent.

We specified the transition matrix, $\boldsymbol{G}$, by identifying three types of sequence pair: sequences from two juveniles (i.e. newly born in the current breeding cycle), sequences from two adults (i.e. individuals surviving from the previous breeding cycle), and sequences from one juvenile and one adult (these types are labelled,,-+ \pm respectively). The transition matrix can be written as $G=G^{-}+G^{ \pm}+G^{+}$where

$$
G^{-}=(1-v)^{2}\left(\begin{array}{ccc}
0 & 1 /(1-v) & 0 \\
\alpha^{-} / 2 N & \alpha^{-}(N-1) / N & 1-\alpha^{-} \\
\beta^{-} / 2 N & \beta^{-}(N-1) / N & 1-\beta^{-}
\end{array}\right)
$$

is the transition matrix when the both sequences in the pair are from juveniles (possibly the same juvenile),

$$
G^{ \pm}=2 v(1-v)\left(\begin{array}{ccc}
0 & 0 & 0 \\
\alpha^{ \pm} / 2 N & \alpha^{ \pm}(N-1) / N & 1-\alpha^{ \pm} \\
\beta^{ \pm} / 2 N & \beta^{ \pm}(N-1) / N & 1-\beta^{ \pm}
\end{array}\right)
$$

is the transition matrix when one sequence is from a juvenile and one from an adult and

$$
G^{+}=v^{2}\left(\begin{array}{ccc}
1 / v & 0 & 0 \\
0 & \alpha^{+} & 1-\alpha^{+} \\
0 & \beta^{+} & 1-\beta^{+}
\end{array}\right)
$$

is the transition matrix when the both sequences in the pair are from adults (possibly the same adult). The other parameters in the many-deme limit are $\alpha^{-}=\left(1-m_{j}\right)^{2}, \alpha^{ \pm}=\left(1-m_{j}\right)\left(1-m_{a}\right), \alpha^{+}=$ $\left(1-m_{a}\right)^{2}$, with $m_{j}$ and $m_{a}$ the juvenile and adult migration rates, respectively (i.e., $m_{j}$ and $m_{a}$ represent natal and breeding dispersal). The parameters $\beta^{X}$ make a negligible contribution to $F_{S T}$ in the many-deme limits because they are inversely proportional to the number of demes. 
Substituting equation 3a-c into equation 1 and solving, and taking the many-deme limit gives

$$
\begin{aligned}
& \mathrm{T}_{1}=\mathrm{T}_{2}=2 N_{a} D /\left(1-v^{2}\right) \\
& \mathrm{T}_{3}=\mathrm{T}_{2}+D\left(1-m_{j}\right)(1+p) M /\left[\left(1-M^{2}\right)(1+v)\right]
\end{aligned}
$$

where $\mathrm{M}=(1-v)\left(1-m_{j}\right)+v\left(1-m_{a}\right), p=v\left(1-m_{a}\right) / M$ and time units are in breeding cycles. To express these coalescence times in numbers of generations they should be divided by generation time (equal to $1 /(1-v)$ ).

Substituting equations 4 into equations 2 gives the $F$-statistics, $F_{I S}=0$ and an expression for $F_{S T}$ in the small mutation limit of

$$
\frac{1-F_{S T}}{F_{S T}}=2 N_{a} \frac{1-M^{2}}{M^{2}} \frac{1}{1-p^{2}}
$$

For non-overlapping generations $(v=0)$ and small migration rates equation 5 gives the classic result $\left(1-F_{S T}\right) / F_{S T}=4 N_{a} m_{j}$ (Wright 1931). The model also correctly predicts the inbreeding effective population size $N_{e}=N_{a} /(1+v)$ for a single isolated population with overlapping generations (Felsenstein 1971; Hill 1972), equivalent to the case when $m_{j}=m_{a}=0$.

Equation 5 shows how the genetic differentiation among ivory gull colonies depends upon adult survival $(v)$, effective colony size $\left(N_{a}\right)$, natal dispersal $\left(m_{j}\right)$ and breeding dispersal $\left(m_{a}\right)$. Adult annual survival rate was estimated to $v=0.86 \pm 0.04(95 \%$ CI: $0.75 ; 0.91)$ (Stenhouse et al. 2004). We used our model with the mean annual survival rate, $v=0.86$ and the upper limit of the confidence interval $v=0.91$. Using a higher survival value will tend to underestimate migration rates, making our interpretation more conservative. Effective colony size $N_{a}$ cannot be precisely parameterized because contrary to our model's assumptions the number of breeding adults is variable across colonies. Known colony sizes (reviewed in Table 3) show a skewed distribution, with a few large colonies (in the order of $100-2000$ breeding pairs) and many smaller ones (below 100 pairs). Furthermore we did not know the prevalence and yearto-year behavior of adults that are apparently non-breeding at some observation time point. 
Such individuals can inflate $N_{a}$ if they have or will enter reproduction at some other breeding

season. Based upon i) field observations of colony sizes (Table 3), ii) the fact that low variance in reproductive success should inflate local effective numbers of breeders (see results for $N_{b} / N_{c}$ in colonies Amdrup Land and Station Nord), and iii) remaining uncertainties about the resulting parameter $N_{a}$, we explored the model behavior for $N_{a}$ ranging 50-1000. Using equation 5 we then worked out the conditions of juvenile and adult migration that would result in a $F_{S T}$ value equal to the observed global $F_{\mathrm{ST}}=0.001$. This allows us to estimate and discuss the lower bound on migration rates for ivory gulls.

\section{RESULTS}

\section{Genetic structure}

Number of alleles, observed and expected heterozygosity in each sample and for each of the 13-microsatellite loci are shown in Table 1 and in Electronic Supplementary Material (Table S1 in Supplementary material 1), respectively. With 13 loci examined in 15 samples, nine locus/site combinations showed a significant deficit in heterozygotes. There was no consistent pattern across samples or loci, and only one locus in one sample (B125, Schmidt Island, Russia) remains significant if one corrects for multiple testing. Yet it is plausible that a small number of allelic dropouts remained undetected in genotypes obtained from shed feathers despite marker selection and genotyping repetitions. The number of genotyping repetitions that we used is based upon average error rates reported in Yannic et al. (2011) but individual shed feathers may happen to be unusually poor sometimes (Yannic et al. 2011). For this reason, we reported differentiation statistics with and without data from shed feathers. The mean observed heterozygosity $(0.63-0.85)$ and mean expected heterozygosity $(0.73-0.82)$ across loci are shown in Table 1. 
No genetic differentiation was observed among breeding samples $\left(n=6, F_{\mathrm{ST}}=0.000,95 \% \mathrm{CI}\right.$ : $-0.006 ; 0.005 ; G$ statistic permutation test $p=0.61$, Fisher's Exact Test $p=0.40$; Table 2 ) or among samples containing more than 10 individuals $\left(n=9, F_{\mathrm{ST}}=0.000,95 \% \mathrm{CI}\right.$ : $0.002 ; 0.003 ; G$ statistic permutation test $p=0.15$, Fisher's Exact Test $p=0.14$; Table S2 in Supplementary material 1), while very low and non-significant differentiation was found overall adult samples $\left(n=15, F_{\mathrm{ST}}=0.001,95 \% \mathrm{CI}:-0.002 ; 0.005 ; G\right.$ statistic permutation test $p=0.09$, Fisher's Exact Test $p=0.09$; Table 2). This figure was unaffected when removing all shed feather samples $\left(n=8, F_{\mathrm{ST}}=0.000\right)$. Pairwise $F_{\mathrm{ST}}$ values were also very low, ranging from -0.032 to 0.043 and none of these pairwise values was significant after correction for multiple testing (Benjamimi-Yekutieli correction; Table S3 in Supplementary material 1). There was no significant difference in relatedness among breeders $v s$ among unknown birds sampled the same year in the same colony (i.e., Station Nord in 2009: "Effect of transient individuals on genetic structure" section in Supplementary material 1), suggesting that breeders and unknown birds belong to a homogeneous pool. These results were further confirmed by model-based clustering that suggests that our ivory gulls most likely form one worldwide population ("Model-based clustering" section in Supplementary material 1) and by the absence of isolation-by-distance over long distance ("Isolation by distance" section in Supplementary material 1).

Simulations demonstrated that our sample sizes and genetic markers provided sufficient power to detect weak population structure. Population structure was found significant for all simulated populations (i.e. power $=100 \%$ ) with an $F_{\mathrm{ST}}$ of 0.006 when using all adult sampling sites ( $n=17$; Figure 2$)$. Even when $F_{\text {ST }}$ was reduced to 0.0035 , structure was correctly detected in $90 \%$ of the simulations. For $F_{\mathrm{ST}}$ values as low as, or lower than the observed value (i.e., global $F_{\mathrm{ST}}$ among all adults $=0.001$ ), power drops to $25 \%$. When using only breeders sampling sites ( $n=6$ sites), the sample sizes and the genetic markers contain 
sufficient power to detect population structure with $90 \%$ accuracy for simulated populations with $F_{\mathrm{ST}}$ values $\geq 0.007$ (Figure 2 ).

\section{Reproductive success and effective number of breeders}

In the colony Amdrup Land, we counted 98 adults (49 nests) with one offspring, 82 adults (41 nests) with two offspring, and 12 adults (6 nests) with an unknown number of offspring (Yannic et al. 2014a). Assuming that the latter show the same distribution of reproductive success than all other adults, this gives $k \approx 1.46, V_{k} \approx 0.25$, and $N_{b} \approx 445$. In Station Nord we observed 24 adults with one offspring and 48 adults with two, which gives $k \approx 1.67, V_{k} \approx 0.23$, and $N_{b} \approx 148$.

Genetic parentage assignment at Station Nord identified the two parents (from our sample of adults) for 6 juveniles out of 20 . Twelve additional juveniles had one of their parents identified from the candidate adults. The "second parents" of these juveniles and the two parents of the remaining juveniles $(n=2)$ were not identified from the adult samples but their genotype was reconstructed by the software COLONY, meaning that these adults could still be used to check for extra-pair paternity (e.g., if one unsampled male had sired three of our offspring with different unsampled females, this would be visible in the data). As it turned out, the parent-offspring relationships observed in the field were all confirmed by the genetic assignment (that is, for all the individuals with a DNA sample available), with one exception: one adult that was observed caring for a juvenile did not appear to be its genetic parent.

Moreover, this true parent was identified from our sample of adults and it was found to have a second offspring with a different mating partner (field observation, independently confirmed by the genetic data). This suggests one plausible event of extra-pair paternity.

We repeated these analyses in the colony of Amdrup Land, where 65 juveniles (but no parents) were sampled. But with such small clutch size (one or two offspring in general) and 
without any actual parent genotyped, we did not succeed to recover reliable sibship information in this colony (data not shown).

In summary, observable parental behavior seems a reliable indicator of parentage, and field observations suggest that the effective breeding size $N_{b}$ is approximately twice the census colony size $N_{c}$. This figure results from the near-zero variance in breeding success among birds seen in colonies. This variance could be slightly inflated by extra-pair paternity, but with very little consequences for the $N_{b} / N_{c}$ ratio (e.g., $N_{b}$ decreases from 148 to 142 in colony Station Nord if one considers one event of extra-pair paternity where one bird has no success and another one has fathered three offspring).

\section{Model of genetic structure: natal versus breeding dispersal}

We explored the conditions of natal dispersal (dispersal of juveniles) and breeding dispersal (movement of adults among colonies across breeding seasons) that would be consistent with the low level of observed genetic structure.

A general result obtained with the model is that breeding dispersal is very effective at homogenizing the distribution of the genetic variation across populations in long-lived species with overlapping generations. For instance with the ivory gulls, with $v=0.91$ (Figure 3B) and $N_{a}=1000$ and no natal dispersal (that is, perfect philopatry) then a breeding dispersal of only $4.6 \%$ is required to yield an $F_{\mathrm{ST}}$ as low as 0.001 . By contrast, above $30 \%$ natal dispersal would be required in the absence of breeding dispersal.

The above scenario is conservative, providing lower bounds on dispersal rates because we used our highest observation of global $F_{\mathrm{ST}}\left(F_{\mathrm{ST}}=0.001\right.$; see Table 2$)$, large colony size, and high survival. A slightly less conservative scenario $\left(F_{\mathrm{ST}}=0.001, N_{\mathrm{a}}=500, v=0.86\right.$, visible in Figure 3A) gives: $14 \%$ breeding dispersal or $48 \%$ natal dispersal (or any combination along the $F_{\mathrm{ST}}=0.001$ contour line in Figure 3A). Any smaller (i.e., less conservative) value for $N_{a}$ 
or $F_{\mathrm{ST}}$ will increase the minimum level of dispersal. As expected, predictions of genetic structure were highly sensitive to effective colony size (as shown by the different contour lines within Figures 2A and 2B) and survival (compare Figure 3A against 3B).

\section{Discussion}

The key finding from this research is the striking genetic homogeneity of the ivory gull across its entire distribution range. Even with conservative assumptions for local effective breeding numbers and survival rate this suggests that gene flow regularly occurs among distant regions in order for populations to become, and remain, genetically homogenous. We develop below the interpretation of these results indicating genetic homogeneity among populations separated by up to $2800 \mathrm{~km}$.

\section{A single Arctic-wide population}

Information retrieved from microsatellites suggests that the ivory gull represents a single, Arctic-wide metapopulation. We found no significant genetic differentiation among breeding colonies of ivory gull $\left(F_{\mathrm{ST}}=0.000, \mathrm{Cl}_{95 \%}:-0.006 ; 0.005\right)$ or among overall adult samples $\left(F_{\mathrm{ST}}\right.$ $\left.=0.001, \mathrm{CI}_{95 \%}:-0.002 ; 0.005\right)$. We did not observe significant isolation-by-distance among breeding colonies and among overall adult samples across the range of the species ("Isolation by distance" section in Supplementary material 1). These results agree with the weak differentiation found using mitochondrial data (Royston and Carr 2014 and this study; Supplementary material 1).

This absence of genetic structure is a priori not surprising for a species capable of travelling thousands of kilometers either on single foraging trips or to reach its wintering grounds (Gilg et al. 2010). Genetic homogeneity is, however, not the rule in seabird species with similar flying capability. Out of forty-seven seabird species reviewed by (Friesen et al. 2007), only 
few were reported to have as little genetic structure as the ivory gull. The grey-faced petrel

Pterodroma macroptera gouldi (Lawrence et al. 2014), the little auk Alle alle (WojczulanisJakubas et al. 2014) and the wandering albatross Diomedea exulans (Milot et al. 2008) are examples of seabird that present weak genetic structure throughout their distribution. But the vast majority of seabird species rather seem to show a stronger level of genetic divergence, even among geographically proximate colonies (e.g., the Hawaiian petrel Pterodroma sandwichensis (Welch et al. 2012) or Cory's shearwater Calonectris diomedea (Genovart et al. 2013). Genetic divergence among seabird populations inhabiting the Polar Regions seems then to be generally lower in comparison with those breeding at lower latitudes.

Patterns of genetic structuring in species capable of long-distance dispersal may be driven by multiple mechanisms, including restricted gene flow as a result of high natal philopatry, cryptic barriers to dispersal, or behavioral mechanisms (Friesen et al. 2007). In addition, local adaptation to differing ecological conditions and strong selective pressures may promote geographic patterns of differentiation. Our results show that such gene flow limiting processes are not at work in the ivory gull population and high intercolony dispersal genetically homogenizes the populations. It is however worth noting that our results are based on neutral genetic loci (i.e., microsatellite loci) and adaptive differences could exist among colonies.

Our interpretation of the data assumes that the $F_{\mathrm{ST}}$ is at migration-drift equilibrium. With small deme size and large migration rates, $F_{\mathrm{ST}}$ reaches equilibrium very rapidly [i.e. in the order of a few dozen of generations, Rousset (2004)], contrary to gene diversity which may take a much longer time to reach equilibrium (Crow and Aoki 1984). The hypothesis that we believe to be most parsimonious in the case of ivory gulls is that $F_{\mathrm{ST}}$ has long been equilibrated and there is large-scale genetic exchange between colonies, most likely due to a combination of natal and breeding dispersal. An alternative hypothesis may be that the 
worldwide population is sub-structured into poorly connected demes and the genetic homogeneity observed in ivory gull today is a consequence of the evolutionary history of the species, i.e., a northward expansion of population from a single homogeneous refugia after the deglaciation of the Arctic region (e.g., Wojczulanis-Jakubas et al. 2014). However, while it is temperate species were restricted to refugial area during glacial stages, taxa found in more northern latitudes today are known to have had greater distributions during the glacial phases (e.g., Lorenzen et al. 2011; Yannic et al. 2014b). This suggests that colder adapted species were in more restricted areas during interglacial and not during glacial stages (Stewart and Dalen 2008; Stewart and Lister 2001). From this perspective, ivory gulls could be said to be in "refugia" today and not necessarily in the Late Pleistocene.

\section{Natal versus breeding dispersal}

To disentangle the respective role of natal dispersal, i.e. the movement from the natal site to the site of first reproduction (Greenwood and Harvey 1982), and breeding dispersal, i.e. movement between successive breeding attempts in the ivory gull, we developed an infinite island model with overlapping generations that we used to calculate the expected global $F_{\mathrm{ST}}$ at equilibrium for a range of adult and juvenile migration rate scenarios. Our results show that breeding dispersal is very effective at reducing genetic differentiation across populations in long-lived seabird with overlapping generations. We used this model here in an attempt to better understand the demo-genetics of a featured high-artic seabird species, but the modeling framework that we presented here is very general. Our model could be used further to look at the effect of overlapping generations and variations in natal vs breeding dispersal, two aspects that have largely been ignored from empirical molecular ecology research so far. 
Long-term field data are lacking for the ivory gull (see next section below), but breeding dispersal is thought to be less than natal dispersal for seabirds in general (e.g., Gauthier et al. 2010). In many long-lived seabird species with low reproductive rate, breeding philopatry is believed to be very high, although actual dispersal rates have been rigorously quantified for a few species only: roseate tern Sterna dougallii (ma=0.00-0.09 yr-1; Lebreton et al. 2003), common tern Sterna hirundo (ma=0.04-0.08 yr-1; Nisbet and Cam 2002), wandering albatross (ma=0.00-0.30 yr-1; Gauthier et al. 2010) or Adélie penguin Pygoscelis adeliae (ma< $0.01 \mathrm{yr}-1$; Dugger et al. 2010). In these species, breeding dispersal rates appear to be very low and strongly limited by the distance among colonies, although dispersal could vary with ice conditions (e.g., Dugger et al. 2010). These observations suggest that there are behavioral constraints on adult movement amongst breeding colonies (Friesen et al. 2007). Many seabirds have an extraordinary ability to travel long distances and yet show evidence of restricted gene flow and exhibit high levels of philopatry, sometimes returning to breed within a few meters of their natal nest (Friesen et al. 2007). The ultimate causes for such philopatric behavior are not known, although familiarity with natal and/or previous breeding habitats (Friesen et al. 2007) and fitness costs incurred by dispersal itself (Clobert et al. 2001) seem likely to be involved.

Our results contradict in some ways the general pattern found in the literature (Friesen et al. 2007). According to our models (and recalling that we are considering lower bounds on migration rates), it seems unlikely that the low breeding dispersal rates reported above for seabirds are compatible with the genetic pattern observed here for the ivory gull, even if natal dispersal is strong. To be compatible with our observations, a level of breeding dispersal below 0.1 would have to be associated with extremely frequent natal dispersal (that is, a complete mixture of young adults, see Figure 3 with $m_{a}$ in $0-0.1$ ). Demographic data from the 
field will be very important to test this suggestion. Information on the movement behavior of juvenile birds and additional estimates of adult survival would be particularly valuable.

\section{Movement of adult ivory gulls inferred from ecological data}

Ring recoveries are in line with large-scale movement in ivory gulls and suggest long distance travel events (> $3400 \mathrm{~km}$; Gaston et al. 2008; Lyngs 2003). However, it is often not known whether recovered birds were actually breeding in the areas where they were found, making inferences about the frequency of effective dispersal at large spatial scales difficult. Recent advances in movement ecology using satellite transmitters indicated similar post-breeding flyways over long distance for ivory gulls breeding in the north east Atlantic, i.e., for birds breeeding in north Greenland, Svalbard and Franz Josef Land, Russia (Gilg et al. 2010). Wintering grounds were reached in December, in southeast Greenland and along the Labrador Sea ice-edge, where Canadian birds also overwinter or in the Bering Strait region (Gilg et al. 2010; Mallory et al. 2008). Data also indicate that birds from different colonies, however, migrate eastwards towards wintering area in the Bering Strait region, hence demonstrating a bi-directional migration pattern (Figure 1).

Similar flyways and wintering area for birds from different colonies over the entire species range may result in the recruitment of birds to distant colonies after the overwinter period (i.e., birds never return to the natal colony). Such movement events may be accidental (i.e., birds are unable to return to the natal area) or may reflect behavioral variation in philopatry among individuals (Weatherhead and Forbes 1994). The tendency for birds to disperse may also be linked to the conditions in the natal colony the year they were born and to the local dynamics of the colonies that they recruit to. Such long-distance dispersal events or reshuffling of individuals on the pre-breeding flyways may be sufficient to eliminate the traces of regional structure among populations. The fidelity of ivory gulls to the breeding site 
is unknown but at least some marked individuals return to the same breeding colony from one year to the next (MacDonald 1976), and an example of extreme breeding site fidelity has been reported (Mallory et al. 2012). Populations that breed on flat land of Russia, where the highest census population size are observed (Table 3), are often prone to move from site to site (de Korte and Volkov 1993).

\section{Dispersal and connectivity under climate change}

Climate change is geographically shifting the climatic envelope of many species and this is predicted to occur rapidly in the Arctic (up to $\sim 0.40 \mathrm{~km} / \mathrm{yr}$; Loarie et al. 2009). The capacity of populations to respond to climate change will depend of evolutionary and demographic processes (i.e., plasticity, adaptation or migration) (Bourne et al. 2014). Specifically, level of additive genetic variance within population can directly influence evolutionary outcomes in response to environmental change by providing the necessary genetic variation upon which selection can act (Bourne et al. 2014; Lande and Shannon 1996). Now, our genetic results suggest high connectivity and gene flow among populations that furthermore still maintain high level of genetic diversity and higher evolutionary potential within each population, despite recent declines in population census size in some regions (e.g., Canada).

Following these results, two important points call however for further investigations. First, the very high level of genetic connectivity revealed by this study remains difficult to translate into an estimate of demographic connectivity. We have made some efforts to disentangle the effects of dispersal from local population size, but there remains too much uncertainty in our estimates to determine whether the extent of dispersal that ensures genetic homogeneity is enough to have an effect on local demography (a relevant issue in high gene flow species; Waples 1998; Waples and Gaggiotti 2006). Information on the behavior of first- and secondyear ivory gulls and adult survival estimates will be key to reduce the space of dispersal 
parameters that are compatible with our genetic findings. We need to know more about the movement of birds between their natal site and first breeding attempt. Second, while our findings show that the genetic diversity within colonies is currently high, further studies will have to determine whether this state is stable or show signs of disequilibrium (e.g. in line with findings from demographic surveys that show a strong decline in colony numbers and size). The effects of overlapping generations and metapopulation functioning will have to be taken into account when looking for genetic signatures of demographic stability or decline (Broquet et al. 2010; Chikhi et al. 2010; Leblois et al. 2006).

\section{Conservation implications}

Resources for conservation management of endangered species are always limited, and therefore an understanding of population differentiation and connectivity can help identify conservation priorities and inform management decisions. Here our results indicate that the ivory gull should be considered a wide-range, genetically homogeneous metapopulation. The lack of population genetic structure found among colonies, in tandem with independent evidence of movement among colonies, suggests ongoing effective dispersal is occurring across ocean basins. This intercolony movement over large spatial scales can potentially enhance the persistence of highly fragmented seabird colonies. The generally large nonbreeding component of populations may also play an important role on the structure, dynamics and persistence of populations in buffering the effects of mortality with compensatory recruitment (although it may also hide a recent population decline, Penteriani et al. 2011; Votier et al. 2008). Our study suggests immigrant recruitment from distant populations could have similar effects. Understanding patterns of connectivity among disjunct populations of highly vagile colonial seabirds is vital to appropriately manage their populations and help predict the effect of future environmental change. 


\section{Acknowledgments}

632

634

636

This work was supported by grants from foundation Ellis Elliot (Switzerland), Société vaudoise des Sciences naturelles (Switzerland), and Nos Oiseaux (Switzerland) to GY, by a foundation Agassiz (Switzerland) grant to TB and by the Nicolas Perrin's research group, Department of Ecology and Evolution at University of Lausanne, Switzerland. Field work in Greenland was supported by the National Geographic Society, Prix Gore-Tex initiative, Fondation Avenir Finance, the Arctic Ocean Diversity Census of Marine Life Project, CNES, CLS and F. Paulsen. The ivory gull project was part of the work plan of the Joint NorwegianRussian Commission on Environmental Protection and fieldwork in Norway and Russia was funded by the Norwegian Ministry of Environment, the Norwegian Polar Institute, Arctic and Antarctic Research Institute and Russian IPY 2007/08 program. We are grateful to Emmanuelle Pouivé, Brigitte Sabard, Vladimir Sokolov and Oleg Prodan, Vorkuta helicopter crew commanded by Sergey Kiryushkin for logistical assistance, Russian colleagues Mikhail Ivanov, Andrey and Elena Volkov for participating in fieldwork. Constructive comments by Nigel G. Yoccoz and two anonymous referees improved the manuscript. 


\section{References}

ACIA (2004) Impacts of a Warming Arctic: Arctic Climate Impact Assessment. Cambridge University Press, Cambridge, UK.

Bell G, Gonzalez A (2011) Adaptation and evolutionary rescue in metapopulations experiencing environmental deterioration. Science 332:1327-1330

BirdLife International (2012) Pagophila eburnea. In: IUCN 2013. IUCN Red List of Threatened Species. Version 2013.2, http://www.iucnredlist.org Accessed 23 January 2014

Bourne EC, Bocedi G, Travis JMJ, Pakeman RJ, Brooker RW, Schiffers K (2014) Between migration load and evolutionary rescue: dispersal, adaptation and the response of spatially structured populations to environmental change. Proc R Soc Lond, Ser B: Biol Sci 281:20132795

Broquet T, Angelone S, Jaquiéry J, Joly P, Léna JP, Lengagne T, Plénet S, Luquet E, Perrin N (2010) Genetic bottlenecks driven by population disconnection. Conserv Biol 24:1596-1605

Broquet T, Petit EJ (2009) Molecular Estimation of Dispersal for Ecology and Population Genetics. Annu Rev Ecol Evol Syst 40:193-216

Chen IC, Hill JK, Ohlemüller R, Roy DB, Thomas CD (2011) Rapid range shifts of species associated with high levels of climate warming. Science 333:1024-1026

Chikhi L, Sousa VC, Luisi P, Goossens B, Beaumont MA (2010) The confounding effects of population structure, genetic diversity and the sampling scheme on the detection and quantification of population size changes. Genetics 186:983-995

Clobert J, Danchin E, Dhondt A, Nichols J (2001) Dispersal. Oxford University Press, New York

COSEWIC (2006) COSEWIC Assessment on the Ivory Gull Pagophila eburnea in Canada Committee on the Status of Endangered Wildlife in Canada, Ottawa, ON, Canada

Crow JF, Aoki K (1984) Group selection for a polygenic behavioral trait: estimating the degree of population subdivision. Proc Natl Acad Sci USA 81:6073-6077

de Korte J, Volkov AE (1993) Large colony of ivory gulls Pagophila eburnea at Domashniy Island, Severnaya Zemlya. Sula 7:107-110

Dugger KM, Ainley DG, Lyver POB, Barton K, Ballard G (2010) Survival differences and the effect of environmental instability on breeding dispersal in an Adelie penguin meta-population. Proc Natl Acad Sci USA 107:12375-12380

Environment Canada (2013) Recovery Strategy for the ivory gull (Pagophila eburnea) in Canada. Recovery Planning, Environment Canada, Gatineau, Quebec, Canada

Felsenstein J (1971) Inbreeding and variance effective numbers in populations with overlapping generations. Genetics 168:581-597

Friesen VL, Burg TM, McCoy KD (2007) Mechanisms of population differentiation in seabirds. Mol Ecol 16:1765-1785

Gaston AJ, Brewer D, Diamond AW, Woodsworth EJ, Collins BT (2008) Canadian Atlas of Bird Banding. Volume 2, Seabirds, 1921-1995. Canadian Wildlife Service, Environment Canada, Canada

Gauthier G, Milot E, Weimerskirch H (2010) Small-scale dispersal and survival in a longlived seabird, the wandering albatross. J Anim Ecol 79:879-887

Gavrilo MV (2011) Ivory gull Pagophila eburnea (Phipps, 1774) in the Russian Arctic: breeding patterns of species within the current species range optimum. $\mathrm{PhD}$, SaintPetersburg State University, Saint-Petersburg, Russia

Genovart M, Thibault JC, Igual JM, Bauza-Ribot MD, Rabouam C, Bretagnolle V (2013) Population structure and dispersal patterns within and between Atlantic and Mediterranean populations of a large-range pelagic seabird. Plos One 8 
Gienapp P, Teplitsky C, Alho JS, Mills JA, Merila J (2008) Climate change and evolution: disentangling environmental and genetic responses. Mol Ecol 17:167-178

Gilchrist HG, Mallory ML (2005) Declines in abundance and distribution of the ivory gull (Pagophila eburnea) in Arctic Canada. Biol Conserv 121:303-309

Gilchrist HG, Strøm H, Gavrilo MV, Mosbech A (2008) International ivory gull conservation strategy and action plan vol No. 18. Conservation of Arctic Flora and Fauna (CAFF) International Secretariat, Circumpolar Seabird Group (CBird), Akureyri

Gilg O, Aars J, Fort J, Gauthier G, Gremillet D, Ims RA, Kovacs KM, Meltofte H, Moreau J, Post E, Schmidt NM, Yannic G, Bollache L (2012) Climate change and the ecology and evolution of Arctic vertebrates. Ann N Y Acad Sci 1249:166-190

Gilg O, Boertmann D, Merkel F, Aebischer A, Sabard B (2009) Status of the endangered ivory gull, Pagophila eburnea, in Greenland. Polar Biol 32:1275-1286

Gilg O, Strøm H, Aebischer A, Gavrilo MV, Volkov A, Miljeteig C, Sabard B (2010) Postbreeding movements of the northeast Atlantic ivory gull Pagophila eburnea populations. J Avian Biol 41:532-542

Goudet J (2005) FSTAT: a program to estimate and test gene diversities and fixation indices (version 2.9.3). Available from http://www.unil.ch/dee/page6767_en.html. University of Lausanne, Lausanne

Goudet J, Raymond M, deMeeus T, Rousset F (1996) Testing differentiation in diploid populations. Genetics 144:1933-1940

Greenwood PJ, Harvey PH (1982) The natal and breeding dispersal of birds. Annu Rev Ecol Syst 13:1-21

Hill WG (1972) Effective size of populations with overlapping generations. Theor Popul Biol 3:278-289

Hoenig JM, Heisey DM (2001) The abuse of power: The pervasive fallacy of power calculations for data analysis. The American Statistician 55:19-24

Hoffmann AA, Sgro CM (2011) Climate change and evolutionary adaptation. Nature 470:479-485

IPCC (2007) Climate change 2007: impacts, adaptation and vulnerability. Contribution of working group II to the Fourth Assessment Report of the intergovernmental panel on climate change. Cambridge University Press, New York, USA.

Jones O, Wang J (2009) COLONY: a program for parentage and sibship inference from multilocus genotype data. Mol Ecol Resour 10:551-555

Kimura M (1969) Number of heterozygous nucleotide sites maintained in a finite population due to steady flux of mutations. Genetics 61:893-903

Kimura M, Crow J (1963) The measurement of effective population number. Evolution 17:279-288

Lande R, Shannon S (1996) The role of genetic variation in adaptation and population persistence in a changing environment. Evolution 50:434-437

Laporte V, Charlesworth B (2002) Effective population size and population subdivision in demographically structured populations. Genetics 162:501-519

Lawrence H, Lyver P, Gleeson D (2014) Genetic panmixia in New Zealand Grey-faced Petrel: Implications for conservation and restoration. Emu 114:249-258

Leblois R, Estoup A, Streiff R (2006) Genetics of recent habitat contraction and reduction in population size: does isolation by distance matter? Mol Ecol 15:3601-3615

Lebreton JD, Hines JE, Pradel R, Nichols JD, Spendelow JA (2003) Estimation by capturerecapture of recruitment and dispersal over several sites. Oikos 101:253-264

Loarie SR, Duffy PB, Hamilton H, Asner GP, Field CB, Ackerly DD (2009) The velocity of climate change. Nature 462:1052-1055 
Lorenzen ED, Nogues-Bravo D, Orlando L, Weinstock J, Binladen J, Marske KA, Ugan A, Borregaard MK, Gilbert MTP, Nielsen R, Ho SYW, Goebel T, Graf KE, Byers D, Stenderup JT, Rasmussen M, Campos PF, Leonard JA, Koepfli KP, Froese D, Zazula G, Stafford TW, Aaris-Sorensen K, Batra P, Haywood AM, Singarayer JS, Valdes PJ, Boeskorov G, Burns JA, Davydov SP, Haile J, Jenkins DL, Kosintsev P, Kuznetsova T, Lai XL, Martin LD, McDonald HG, Mol D, Meldgaard M, Munch K, Stephan E, Sablin M, Sommer RS, Sipko T, Scott E, Suchard MA, Tikhonov A, Willerslev R, Wayne RK, Cooper A, Hofreiter M, Sher A, Shapiro B, Rahbek C, Willerslev E (2011) Species-specific responses of Late Quaternary megafauna to climate and humans. Nature 479:359-364

Lyngs P (2003) Migration and winter ranges of birds in Greenland: An analysis of ringing recoveries. Dansk Ornitologisk Forenings Tidsskrift 97:1-167

MacDonald SD (1976) Phantoms of the polar pack-ice. Audubon 78:2-19

Mallory ML, Allard KA, Braune BM, Gilchrist HG, Thomas VG (2012) New longevity record for ivory gulls (Pagophila eburnea) and evidence of natal philopatry. Arctic 65:98-101

Mallory ML, Stenhouse IJ, Gilchrist HG, Robertson G, Haney JC, Macdonald SD (2008) Ivory gull (Pagophila eburnea). The Birds of North America Online (A. Poole, Ed.). Ithaca: Cornell Laboratory of Ornithology; Retrieved from The Birds of North America Online: http://bna.birds.cornell.edu/BNA/species/175/. DOI: 10.2173/bna.175.

Milot E, Weimerskirch H, Bernatchez L (2008) The seabird paradox: dispersal, genetic structure and population dynamics in a highly mobile, but philopatric albatross species. Mol Ecol 17:1658-1673

Nisbet ICT, Cam E (2002) Test for age-specificity in survival of the common tern. Journal of Applied Statistics 29:65-83

Parmesan C (2006) Ecological and evolutionary responses to recent climate change. Annual Review of Ecology Evolution and Systematics 37:637-669

Penteriani V, Ferrer M, Delgado MM (2011) Floater strategies and dynamics in birds, and their importance in conservation biology: towards an understanding of nonbreeders in avian populations. Anim Conserv 14:233-241

Rousset F (2001) Genetic approaches to the estimation of dispersal rates. In: Clobert J, Danchin E, Dhondt AA, Nichols JD (eds) Dispersal. Oxford University Press, New York,

Rousset F (2004) Genetic Structure and Selection in Subdivided Populations. Monographs in Population Biology. Princeton University Press, Princeton and Oxford

Royston S, Carr S (2014) Conservation genetics of high-arctic Gull species at risk: I. Diversity in the mtDNA control region of circumpolar populations of the Endangered Ivory Gull (Pagophila eburnea). Mitochondrial DNA 26:1-4

Ryman N, Palm S (2006) POWSIM: a computer program for assessing statistical power when testing for genetic differentiation. Mol Ecol Notes 6:600-602

Slatkin M (1991) Inbreeding coefficients and coalescence times. Genetics Research 58:167175

Spencer NC, Gilchrist HG, Mallory ML (2014) Annual movement patterns of endangered ivory gulls: the importance of sea ice. Plos One 9:e115231

Stenhouse IJ, Robertson GJ, Gilchrist. HG (2004) Recoveries and survival rates of ivory gulls (Pagophila eburnea) banded in Nunavut, Canada, 1971-1999. Waterbirds 27:486-492

Stewart JR, Dalen L (2008) Is the glacial refugium concept relevant for northern species? A comment on Pruett and Winker 2005. Clim Change 86:19-22

Stewart JR, Lister A (2001) Cryptic northern refugia and the origins of the modern biota. Trends in Ecology and Evolution 16:608-613 
Travis JMJ, Delgado M, Bocedi G, Baguette M, Barton K, Bonte D, Boulangeat I, Hodgson JA, Kubisch A, Penteriani V, Saastamoinen M, Stevens VM, Bullock JM (2013) Dispersal and species' responses to climate change. Oikos 122:1532-1540

Votier SC, Birkhead TR, Oro D, Trinder M, Grantham MJ, Clark JA, McCleery RH, Hatchwell BJ (2008) Recruitment and survival of immature seabirds in relation to oil spills and climate variability. J Anim Ecol 77:974-983

Wakeley J (2009) Coalescent theory. Roberts and Company Publishers, Greenwood Village, Colorado

Wang J (2012) Computationally efficient sibship and parentage assignment from multilocus marker data. Genetics 191:183-194

Waples RS (1998) Separating the wheat from the chaff: patterns of genetic differentiation in high gene flow species. J Hered 89:438-450

Waples RS, Gaggiotti O (2006) What is a population? An empirical evaluation of some genetic methods for identifying the number of gene pools and their degree of connectivity. Mol Ecol 15:1419-1439

Waples RS, Teel DJ (1990) Conservation genetics of Pacific salmon. I. Temporal changes in allele frequency. Conserv Biol 4:144-156

Weatherhead P, Forbes MRL (1994) Natal philopatry in birds: genetic or ecological influences? Behavioural Ecology 5:426-433

Weir B, Cockerham C (1984) Estimating F-statistics for the analysis of population structure. Evolution 38:1358-1370

Welch AJ, Fleischer RC, James HF, Wiley AE, Ostrom PH, Adams J, Duvall F, Holmes N, $\mathrm{Hu}$ D, Penniman J, Swindle KA (2012) Population divergence and gene flow in an endangered and highly mobile seabird. Heredity 109:19-28

Westneat DF, Stewart IRK (2003) Extra-pair paternity in birds: causes, correlates, and conflict. Annual Review of Ecology, Evolution, and Systematics 34:365-396

Wojczulanis-Jakubas K, Kilikowska A, Harding AMA, Jakubas D, Karnovsky NJ, Steen H, Strom H, Welcker J, Gavrilo M, Lifjeld JT, Johnsen A (2014) Weak population genetic differentiation in the most numerous Arctic seabird, the little auk. Polar Biol 37:621-630

Wright S (1931) Evolution in mendelian populations. Genetics 16:97-159

Yannic G, Aebischer A, Sabard B, Gilg O (2014a) Complete breeding failures in ivory gull following unusual rainy storms in North Greenland. Polar Res 33:22749

Yannic G, Pellissier L, Ortego J, Lecomte N, Couturier S, Cuyler C, Dussault C, Hundermark KJ, Irvine RJ, Jenkins DA, Kolpashikov L, Mager K, Musiani M, Parker KL, Røed KH, Sipko T, Pórisson SG, Weckworth BV, Guisan A, Bernatchez L, Côté SD (2014b) Genetic diversity in caribou linked to past and future climate change. Nature Climate Change 4:132-137

Yannic G, Sermier R, Aebischer A, Gavrilo MV, Gilg O, Miljeteig C, Sabard B, Strom H, Pouive E, Broquet T (2011) Description of microsatellite markers and genotyping performances using feathers and buccal swabs for the ivory gull (Pagophila eburnea). Mol Ecol Resour 11:877-889

Yearsley J, Viard F, Broquet T (2013) The effect of collective dispersal on the genetic structure of a subdivided population. Evolution 67:1649-1659 
Table 1. Estimates of genetic variability for sampled sites of ivory gull (Pagophila eburnea). $N$ gives the number of samples genotyped at 13 microsatellite markers. Statistics include number of alleles $(n A)$, allelic richness (Ar; estimated for $n \geq 10$ individuals and based on min. sample are identified by their abbreviation (Abbr.) throughout the study

\begin{tabular}{|c|c|c|c|c|c|c|c|c|c|c|c|c|c|c|}
\hline ID & Country & $\begin{array}{l}\text { Estimated regional } \\
\text { population }\end{array}$ & Region & Site & Abbr. & Latitude & Longitude & Status & DNA source & $\mathrm{N}$ & $n A$ & $A r$ & $H_{\mathrm{O}}$ & $H_{\mathrm{E}}$ \\
\hline$\# 1$ & \multirow[t]{4}{*}{ Greenland } & \multirow[t]{4}{*}{$>2000$ pairs $^{\mathrm{a}}$} & \multirow[t]{4}{*}{ National Park } & \multirow[t]{3}{*}{ Station Nord } & StNo & 81.60 & -16.66 & adult unknown & swab & 81 & 9.9 & 6.01 & 0.76 & 0.78 \\
\hline$\# 2$ & & & & & $\mathrm{StBr}$ & 81.61 & -16.49 & adult breeding & swab & 25 & 8.3 & 6.08 & 0.77 & 0.78 \\
\hline \#3 & & & & & StJv & 81.61 & -16.49 & juvenile & swab/tissue & $19 / 1$ & 7.6 & 5.95 & 0.82 & 0.79 \\
\hline$\# 4$ & & & & Amdrup Land & AmLa & 80.85 & -14.63 & juvenile & swab/tissue & $33 / 12$ & 9.2 & 6.04 & 0.79 & 0.79 \\
\hline$\# 5$ & \multirow[t]{4}{*}{ Norway } & \multirow[t]{4}{*}{$350-500$ pairs $^{b}$} & \multirow[t]{4}{*}{ Svalbard } & Svenskoya & Sven & 78.72 & 26.63 & adult breeding & blood & 9 & 6.8 & - & 0.84 & 0.82 \\
\hline$\# 6$ & & & & Auga & Auga & 78.50 & 21.74 & adult breeding & swab/blood & $1 / 17$ & 7.5 & 6.05 & 0.76 & 0.78 \\
\hline \#7 & & & & Hübnerbreen & Hübn & 78.41 & 21.69 & adult breeding & swab & 7 & 5.7 & - & 0.85 & 0.76 \\
\hline$\# 8$ & & & & Freemanbreen & Free & 78.38 & 21.43 & adult breeding & swab/plucked feathers & $34 / 2$ & 9.7 & 6.50 & 0.76 & 0.80 \\
\hline \#9 & \multirow[t]{8}{*}{ Russia } & \multirow[t]{8}{*}{$\begin{array}{l}14,500-22,000 \\
\text { pairs }^{c}\end{array}$} & \multirow[t]{3}{*}{ Franz Josef Land } & Nagurskoje & Nagu & 80.72 & 48.22 & adult unknown & shed feathers & 5 & 3.9 & - & 0.63 & 0.73 \\
\hline$\# 10$ & & & & Rudolf Island & Rudo & 81.75 & 58.39 & adult unknown & shed feathers & 17 & 7.4 & 6.12 & 0.67 & 0.79 \\
\hline$\# 11$ & & & & Eva-Liv Island & EvLi & 81.64 & 63.22 & adult unknown & shed feathers & 5 & 4.8 & - & 0.70 & 0.80 \\
\hline$\# 12$ & & & \multirow[t]{4}{*}{ Severnaya Zemlya } & Schmidt Island & SchI & 81.04 & 90.76 & adult unknown & shed feathers & 12 & 6.6 & 5.94 & 0.73 & 0.76 \\
\hline$\# 13$ & & & & Domashny Island & Doma & 79.51 & 94.84 & adult unknown & shed feathers/swab & $17 / 6$ & 8.5 & 6.19 & 0.80 & 0.77 \\
\hline$\# 14$ & & & & Komsomalets Island & Koms & 80.77 & 91.05 & adult unknown & shed feathers & 6 & 5.7 & - & 0.83 & 0.80 \\
\hline$\# 15$ & & & & Sukhaya River & Sukh & 80.77 & 96.75 & juvenile & shed feathers & 7 & 5.8 & - & 0.76 & 0.80 \\
\hline$\# 16$ & & & Kara Sea Islands & Heiberg Islands & HeiI & 77.61 & 101.51 & adult unknown & shed feathers & 4 & 4.2 & - & 0.73 & 0.77 \\
\hline \#17 & \multirow[t]{2}{*}{ Canada } & \multirow[t]{2}{*}{900 pairs $^{\mathrm{d}}$} & \multirow[t]{2}{*}{ Nunavut } & Seymour Island & SeyI & 76.80 & -101.27 & adult breeding & Swab/plucked feathers & 11 & 6.5 & 5.84 & 0.75 & 0.78 \\
\hline$\# 18$ & & & & Ellesmere Island (Alert) & AlEI & 82.50 & -62.33 & adult unknown & blood & 12 & 6.7 & 5.87 & 0.80 & 0.77 \\
\hline & & $\begin{array}{l}19,000-27,000 \\
\text { pairs }\end{array}$ & & & & & & & & 343 & & & & \\
\hline
\end{tabular}

$844{ }^{\mathrm{a}}$ Gilg et al. (2009); ${ }^{\mathrm{b}}$ Gilchrist et al.(2008); ${ }^{\mathrm{c}}$ Gavrilo (2011); ${ }^{\mathrm{d}}$ Environment Canada (2013) 
Table 2. $F_{\text {ST }}$ and exact $G$-test probability values obtained for each autosomal microsatellite and over all loci for two different datasets of ivory gull (Pagophila eburnea)

\begin{tabular}{ccccc}
\hline & \multicolumn{2}{c}{ All adults sites $(n=15)$} & \multicolumn{2}{c}{ Breeding colonies $(n=6)$} \\
\cline { 2 - 5 } Loci & $F_{\text {ST }}$ & P-value & $F_{\text {ST }}$ & $P$-value \\
\hline A111 & -0.005 & 0.78 & -0.014 & 0.94 \\
B125 & 0.002 & 0.32 & 0.004 & 0.61 \\
C7 & 0.009 & 0.83 & 0.003 & 0.45 \\
D126 & 0.004 & 0.27 & 0.002 & 0.62 \\
D5 & 0.004 & 0.17 & 0.013 & 0.16 \\
D9 & -0.008 & 0.76 & 0.001 & 0.23 \\
A112 & -0.003 & 0.65 & -0.012 & 0.99 \\
A132 & 0.010 & 0.37 & -0.011 & 0.85 \\
B114 & -0.009 & 0.76 & -0.010 & 0.92 \\
D103 & 0.006 & 0.11 & -0.004 & 0.62 \\
C6 & 0.002 & 0.20 & 0.018 & 0.54 \\
B103 & 0.008 & 0.62 & -0.006 & 0.08 \\
D1 & 0.007 & 0.04 & 0.013 & 0.04 \\
\hline Over all loci & $\mathbf{0 . 0 0 1}$ & $\mathbf{0 . 0 9}$ & $\mathbf{- 0 . 0 0 0}$ & $\mathbf{0 . 6 1}$ \\
\hline Jackknifing over loci & 0.001 & & 0.003 & \\
Bootstrapping 95\% CI & $-0.002 ; 0.005$ & & $-0.006 ; 0.005$ & \\
\hline
\end{tabular}


Table 3. Census colony size across the breeding distribution of ivory gull (Pagophila eburnea)

\begin{tabular}{rrr}
\hline Country & Number of ivory gulls & Number of colonies \\
\hline Greenland & & \\
n Records between 1854 and 2009 & \\
& $<5$ & 13 \\
& $5-24$ & 6 \\
$25-99$ & 11 \\
& $100-300$ & 5
\end{tabular}

Norway ${ }^{b}$

Maximum records

$\begin{array}{rr}<5 & 7 \\ 4-10 & 5 \\ 11-30 & 19 \\ 31-60 & 7 \\ 61-100 & 3 \\ 101-135 & 1\end{array}$

Russia $^{\mathrm{c}} \quad$ Historically maximum records

$\begin{array}{rr}2-20 & >10 \\ 22-100 & 19 \\ 200-700 & 13 \\ 800-1600 & 7 \\ 2000+ & 5\end{array}$

$\begin{array}{rr}1990 s-2000 s & \\ 2-20 & 0 \\ 22-100 & 17 \\ 200-700 & 11 \\ 800-1600 & 6 \\ 2000+ & 3\end{array}$

Canada $^{4} \quad$ Historically records Between 1976 and 1992

$\begin{array}{rr}<5 & 0 \\ 5-24 & 3 \\ 25-50 & 6 \\ 50-99 & 6 \\ 100-340 & 2\end{array}$

Recent time records between 2001 and 2003

$\begin{array}{rr}<5 & 10 \\ 5-24 & 9 \\ 25-50 & 2 \\ 50-99 & 1 \\ 100-300 & 0\end{array}$

${ }^{1}$ Gilg et al. (2009); ${ }^{2}$ Norwegian Polar Institute; ${ }^{3}$ Maria Gavrilo, unpublished data; ${ }^{4}$ Gilchrist and Mallory 
Figure 1. Map of the study area illustrating the Holarctic distribution of ivory gull (Pagophila eburnea) breeding colonies. Sampling localities are indicated by the ID corresponding with

Table 1; orange dots depict known breeding sites (Gilchrist et al. 2008). Dashed lines:

wintering grounds (variable during the winter and among years according to the extension of the sea-ice; modified from Gilg et al. (2010)). Background map represent the maximum seaice extent in July between 1979-2013 (light blue) and the sea-ice extent in July 2013 (dark blue) (data from the National Snow and Ice Data Centre, Boulder, Colorado; http://nsidc.org/).

Figure 2. Statistical power for obtaining significant outcomes in tests of genetic differentiation involving the specific marker characteristics and sample sizes of ivory gull for i) all adults localities and ii) breeding colonies only. Simulations were performed using POWSIM version 4.1 (Ryman and Palm 2006). The dotted lines indicate the level of genetic differentiation that can be detected with $90 \%$ statistical power for the two data sets.

Figure 3. The parameter space (natal dispersal, $m_{j}$, breeding dispersal, $m_{a}$, effective colony size, $N_{a}$ (contour lines) and adult survival probability, $v$ ) of an overlapping generation model that predicts a global equilibrium $F_{\mathrm{ST}}$ (equation 5) equal to the observed value for ivory gull (using all samples $F_{\mathrm{ST}}=0.001$ ). Given $N_{a}$, the plot shows the combinations of natal and breeding dispersal that are required to yield the observed genetic structure in ivory gulls across its distribution range. The dashed lines in panel A show an example: with $v=0.86$ and $N_{a}=250$, a combination of $25 \%$ natal dispersal and $16.5 \%$ breeding dispersal would predict $F_{\mathrm{ST}}=0.001$ in the simplified conditions of our model 


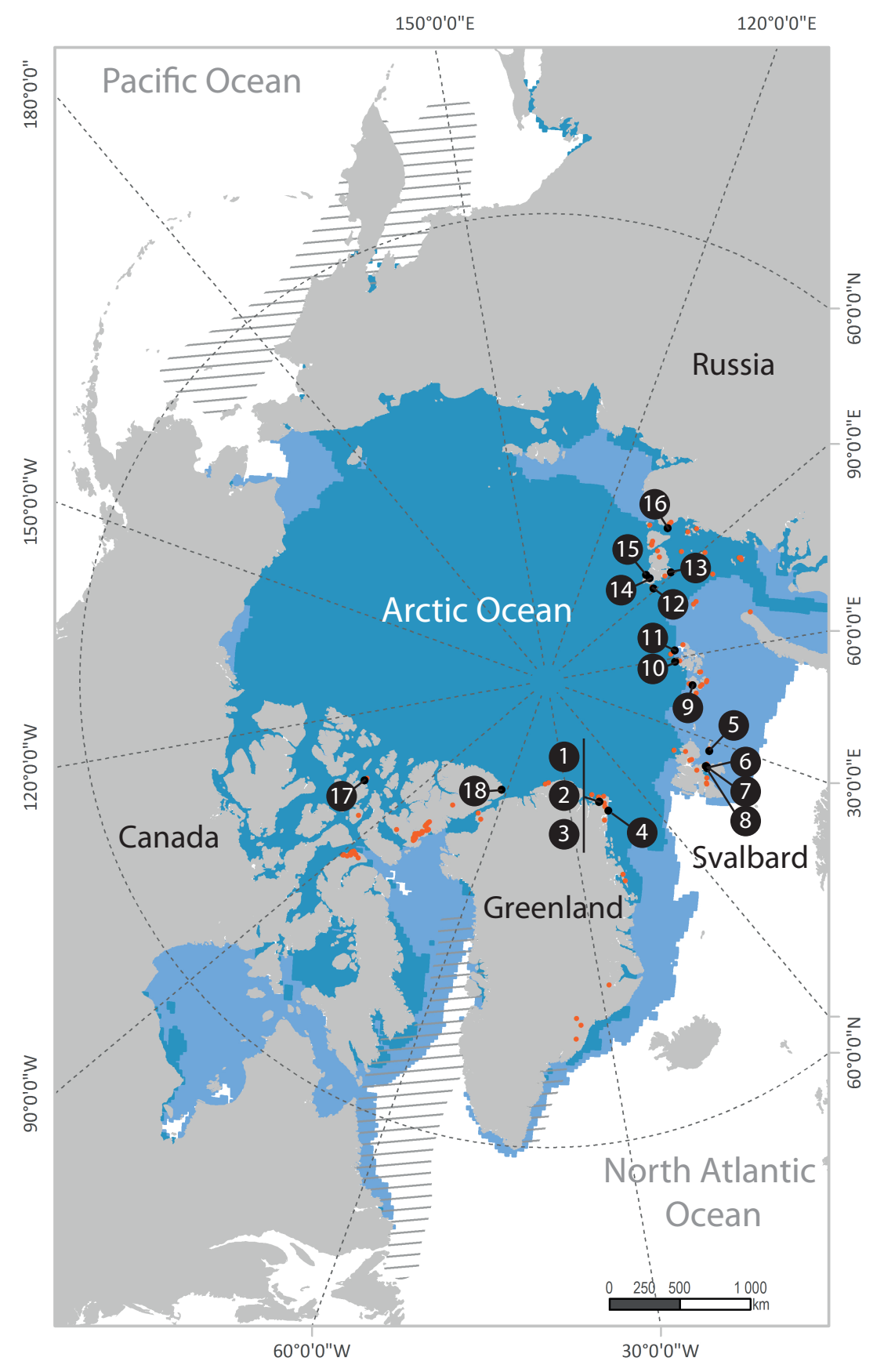




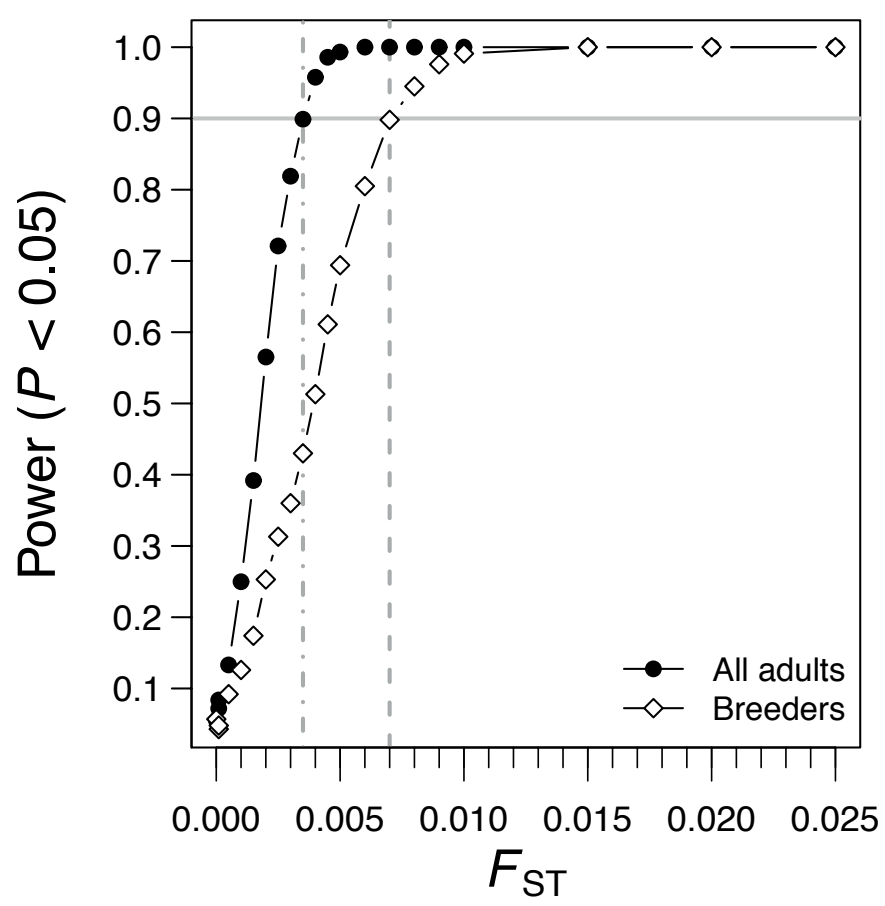


A) Survival $v=0.86$

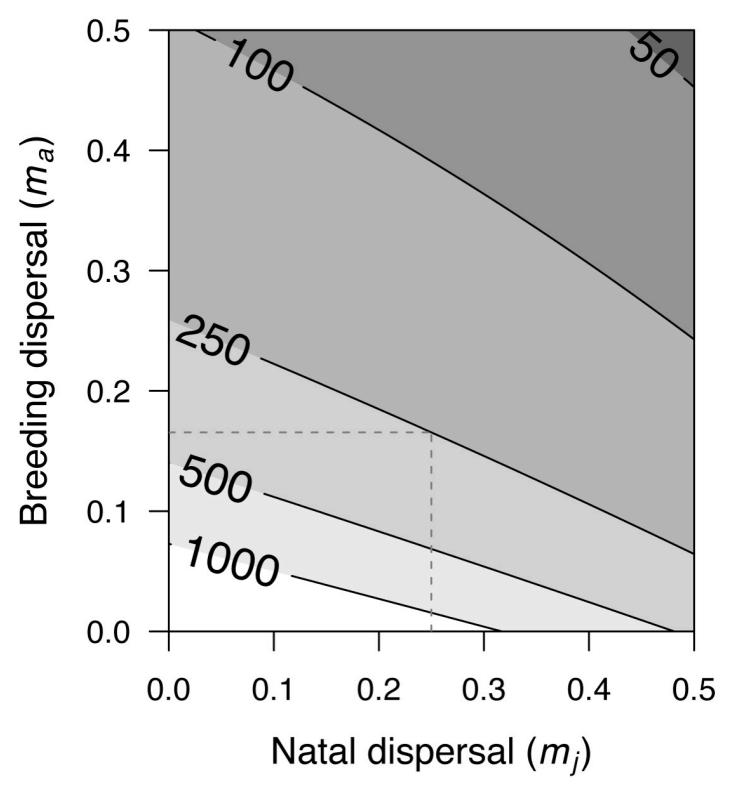

B) Survival $v=0.91$

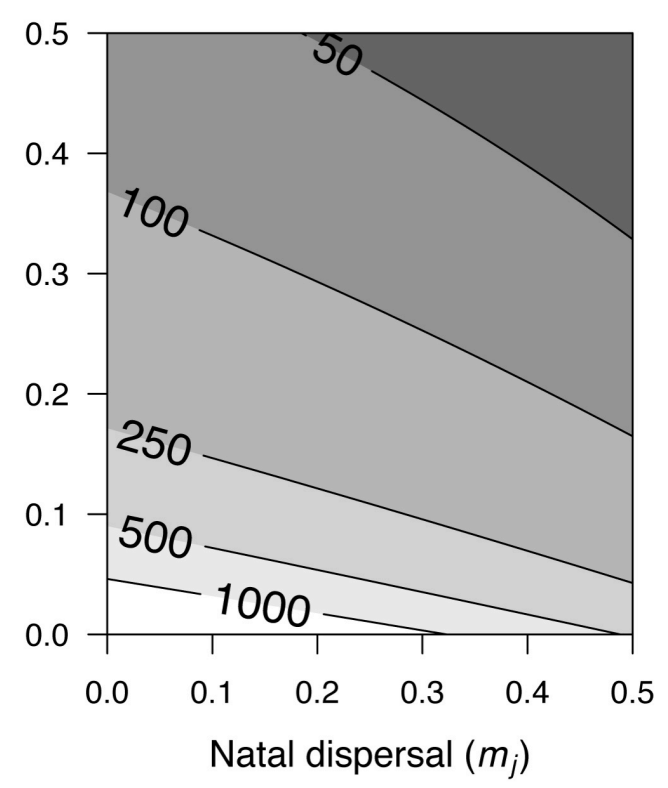

